\title{
AdVerbials ANd InVersion in EARly English SCIENTIFIC WRITING
}

\begin{abstract}
English shifted from being basically verb final in Old English (Traugott 1992: 274) to verb non-final from Middle English onwards (Fischer 1992: 371). From a diachronic standpoint, however, Old English can feature inversion whenever an object, an adverbial or a PP is fronted, while in Middle English it is exclusively witnessed when a wh-element or a negative constituent occupies first position (van Kemenade 1987: 180). Interestingly enough, recent research demonstrates that inversion after fronted adverbials is found in the early Modern English period (Nevalainen 1997: 213).

All this considered, this paper pursues the following objectives: 1) to analyse the occurrence of inversion when adverbials or negative constituents are fronted in early English scientific prose; 2) to investigate the phenomenon across subgenres; and 3) to evaluate the influence of the typology of inversion, the typology of the subject and the taxonomy of inverted verbs. The data come from The Corpus of Early English Medical Writing. ${ }^{1}$
\end{abstract}

\section{Keywords}

Middle English; Early Modern English; inversion; SVO; scientific writing; fronted adverbials; fronted negative constituents

\section{Introduction}

Present Day English (PDE) is often described as a 'fixed word-order language', in which declarative clauses usually occur in the order SVO, except for particular conditions, i.e. the cases of fronting and inversion, in which clause elements that would normally appear after the verb are placed in initial position (Biber et al. 2002: 400; see also Quirk et al. 1985: 51; Carter and McCarthy 2006: 494). ${ }^{2}$ 
Among the cases of fronting that may be found in the English language, Biber et al. have enumerated the following: fronted objects (1), nominals other than objects (2), predicatives (3), non-finite constructions (4) and independent clauses using as or though (5):

(1) The car I could not see.

(2) Whether she liked or not, she would not tell.

(3) The longer the stick the easier it will be to hit the ball.

(4) I shouted at them and go away they did.

(5) Unproductive though they have been in their job.

In addition, the canonical SVO structure of PDE can also be altered by different instances of inversion, in which the verb phrase or the operator comes before the subject. These inverted structures have been defined by Green as "semi-frozen relics of processes more productive in an earlier stage of the language" (1980: 598). ${ }^{3}$ Thus, the phenomenon is triggered by place/time/negative adverbials $(6,7$, 8 , respectively) in initial position (Biber et al. 2002: 405-409): ${ }^{4}$

(6) Over the bridge marched the soldiers.

(7) Then arrived the guests.

(8) Neither do I.

From a diachronic point of view, the situation in Old English (OE) sharply contrasts with that of PDE, the latter being basically verb non-final ${ }^{5}$ whereas the former is essentially verb-final (9) except in main clauses, the verb generally moving to second position (10) (Traugott 1992: 274; Fischer and van der Wurff 2006: 182). ${ }^{6}$

(9) đa se Wisdom đa đis leođ swiđe lustbærlice \& gesceadwislice asungen hæfde, when the wisdom then this song very pleasantly and wisely sung had.

'When wisdom had sung this song so pleasantly and wisely.'

(10) đa hæfde ic đa giet hwylchwugu gemynd on minum mode đære unrotnesse be ic < aer $>$ hæfde.

then had I the still what-little memory in my mind of-the sadness that I before had

'I still remembered some of the sadness I used to feel'

Bo 36.103.23 (Fischer and van der Wurff 2006: 181)

This phenomenon, observed in different West Germanic languages, is the socalled V2, where the operator/verb is optionally placed in second position after an initial subject or object NP, an adverbial phrase, etc. (Stockwell 1984: 583; van Kemenade 1987: 42; Traugott 1992: 275; Fischer 1992: 375; Haeberli and Ingham 2007: 3; Calle-Martín and Miranda-García 2010: 49). ${ }^{7}$ In this vein, Haeberli (2007: 16-17) argues that OE differs from other Germanic languages in four different ways: first, inversion is possible with full DP subjects but not with 
pronominal subjects; ${ }^{8}$ second, even with a full DP subject, inversion is not systematic; third, the finite verb may not occupy the second position after inversion has taken place; and finally, there is a systematic absence of inversion after clause-initial subordinate clauses. The coexistence of these two word-order patterns in $\mathrm{OE}$ has been explained by Hogg in terms of evolution, acknowledging that verb-final is much older than verb-second. This being so, what is witnessed in OE is the "shift away from [verb-final] towards verb-second, [as] when such change occurs, it seems to affect main clauses before subordinate clauses" (2002: 90; see also Fischer 1992: 371).

The transition from $\mathrm{OE}$ to Middle English (ME) is characterized, among other major changes, by the restructuring of word order, English becoming "an almost pure SVO language" (Fischer 1992: 371). According to Fischer et al. (2004: 130), "the main word order difference between Old English and Middle English is that in the latter, considerably fewer OV orders are found". This restructuring came out of the necessity to distinguish subject and object NPs after the loss of inflections in all the main word classes. Furthermore, inversion became much more irregular as it could be triggered after many adverbial phrases (11), although V2 after initial negatives is lost (Fischer 1992: 376). ${ }^{9}$

thus may he curteysly answere

(MEMT: arderne fistula)

Early Modern English (EModE) can be conceived as a transitional period in the development of inversion after fronted adverbials (then, yet or therefore, among others) and negative constituents (never or neither, among others). In this vein, while inversion after fronted adverbials suffers a progressive decline during the EModE period (12), ${ }^{10}$ inversion after fronted negative constituents became the rule (13) (Nevalainen 1997: 204; Rissanen 1999: 265; Ingham 2007: 378). ${ }^{11}$ This is conceived by Fischer as "a renewed grammaticalization of the inversion rule after negatives and implied negatives" (Fischer 1992: 376-377; see also Nevalainen 1997: 587). ${ }^{12}$ Jacobsson, in turn, explains it acknowledging that those clauses with a fronted negative constituent may have an emphatic sense where the negative word attracts the predicative verb (1951: 16).

(12) Then rubbe you the person meanly at home, \& bathe him in faire water. (EMEMT: 1552_Caius_AgainstSweatyngSicknesse)

(13) Nor do they use these to kill, so much as to flie withall. (EMEMT: 1665_Drage_Daimonomageia)

The discussion above has shown that adverbials and negative constituents have been particularly decisive in the development of inversion throughout the history of English. Several approaches have been made to this topic in the literature. While Fries (1940) offers a diachronic account of the status of inversion and Green (1985) assessed the phenomenon in PDE, Jacobsson (1951), Breivik and Swan (1994), 
Nevalainen (1997), and Bækken (2000, 2005) focus on initial adverbials and word order in EModE. The phenomenon has not been, as far as I have investigated, tested in scientific writing, a genre that could certainly shed some new light on the diachronic dimension of the topic in early English. The present paper, therefore, is concerned with those instances of inversion that are triggered by the fronting of adverbials or negative constituents in early English scientific writing with the following objectives: 1) to analyse the occurrence of inversion when adverbials or negative constituents occupy the first position both in main and subordinate clauses in ME and EModE scientific prose; 2) to investigate the proliferation of the phenomenon across the different subgenres; and 3) to evaluate the contribution of conditioning factors such as the kind of inversion, the typology of the subject and the taxonomy of inverted verbs in which the phenomenon occurs.

\section{Methodology}

This study assesses the occurrence of inversion when adverbials (then, therefore, yet, thus) or negative constituents (ne, never, neither, nor) are fronted in early English scientific writing, as they have traditionally triggered inversion at different stages in the history of English. ${ }^{13}$ The source of evidence comes from the Corpus of Early English Medical Writing: Middle English Medical Texts (MEMT) and Early Modern English Medical Texts (EMEMT). These corpora have been selected in the light of the possibilities that they offer when it comes to quantitative and qualitative diachronic studies. While in quantitative terms they amount up to $1,800,000$ words,${ }^{14}$ an adequate language sample of early English scientific writing, their composition allows for the qualitative analysis from a genre perspective. Furthermore, the time span covered by them constitute an ideal input for the study of inversion after fronted adverbials, being the time in which standard Present Day English word order was fixed.

Table 1. Word count for MEMT and EMEMT

\begin{tabular}{|l|r|r|r|r|}
\hline \multicolumn{1}{|c|}{ Corpus } & Specialized texts & Surgical texts & Remedies & Total \\
\hline MEMT & 88,349 & 137,794 & 219,395 & 445,538 \\
EMEMT & 762,667 & 298,352 & 339,068 & $1,400,087$ \\
EMEMT1 1500-1549 & 59,602 & 21,910 & 46,814 & 128,326 \\
EMEMT2 1550-1599 & 162,313 & 102,919 & 92,405 & 357,637 \\
EMEMT3 1600-1659 & 228,135 & 50,771 & 71,047 & 349,953 \\
EMEMT4 1650-1700 & 312,617 & 122,752 & 128,802 & 564,171 \\
\hline
\end{tabular}

MEMT is a corpus of late Middle English scientific writing (1375-1500) containing nearly half a million words that belong to three different scientific genres ranging from "theoretical treatises transmitting specialised top-level knowledge through learned surgical and anatomical texts to simple recipes for practical use 
and miscellaneous collections (Pahta and Taavitsainen 2004: 7; see also CalleMartín and Romero-Barranco 2014, 2015).

EMEMT amounts up to 1,400,000 words divided into general treatises or textbooks, providing a systematic account of the whole field of medicine; treatises on specific topics (texts on specific diseases, on specific methods of diagnosis or treatment, on specific therapeutic substances, on midwifery and children's diseases and on the plague); recipe collections and materia medica, containing both remedy books and formalized pharmacopoeias; regimens and health guides, comprising texts on preventive medicine; surgical and anatomical treatises; and Philosophical Transactions, which consist exclusively of medical texts published as letters or articles in the Philosophical Transactions of the Royal Society (Taavitsainen et al. 2011:22-25). Thus, the material used for the present study allows for the comparison of two different stages in the history of English together with the development of three different genres within scientific writing.

Table 2. Genre categorization of MEMT and EMEMT ${ }^{15}$

\begin{tabular}{|l|l|}
\hline MEMT & EMEMT \\
\hline Specialized texts & General Treatises or textbooks \\
Surgical texts & Treatises on specific topics \\
Remedies and materia medica & Surgical and anatomical treatises \\
& Recipe collections and materia medica \\
- & Regimens and health guides \\
& Philosophical Transactions \\
\hline
\end{tabular}

The data for the study were retrieved by means of AntConc, which provided all the occurrences of the items under analysis in the corpus. However, the process was not straightforward, as manual disambiguation was needed in order to rule out the instances not strictly appearing in initial position, as in (14) and (15) below.

(14) neuer in all my lyf toke I lesse than an hundred shillyng for cure of that sekenes (MEMT: Arderne fistula).

(15) Thus I let him remaine till the next day following in the morning (EMEMT: 1596_Clowes_BookeofObseruations).

\section{Analysis}

The present section is divided into three parts. Consequently, 3.1 and 3.2 will focus on the quantitative approach to the phenomenon as a whole (1350-1700) and from the point of view of genre, respectively. The third part, in turn, assesses the phenomenon qualitatively, exploring the contribution of conditioning factors such as the typology of inversion, the typology of the subject (whether nominal or pronominal), and the verbs with which inversion is witnessed. 


\subsection{Distribution}

This section evaluates the diachronic development of the phenomenon in the period under study. Thus, Table 3 reproduces the absolute and relative figures, together with the normalized frequencies (per 100,000 words), which allow for the comparison between the two historical periods (1350-1500 and 1500-1700).

Table 3. Inversion in MEMT and EMEMT after fronted adverbials and negatives

\begin{tabular}{|c|cc|cc|cc|cc|}
\cline { 2 - 10 } \multicolumn{1}{c|}{} & \multicolumn{4}{c|}{ MEMT } & \multicolumn{4}{c|}{ EMEMT } \\
\cline { 2 - 10 } \multicolumn{1}{c|}{} & \multicolumn{2}{c|}{ Inversion } & \multicolumn{2}{c|}{ SVO } & \multicolumn{2}{c|}{ Inversion } & \multicolumn{2}{c|}{ SVO } \\
\cline { 2 - 10 } \multicolumn{1}{c|}{} & n.f. & $\%$ & n.f. & $\%$ & n.f. & $\%$ & n.f. & $\%$ \\
\hline Adverbials & 16.3 & 39.2 & 25.3 & 60.8 & 41.6 & 18.8 & 179.3 & 81.2 \\
Negatives & 10.5 & 46.07 & 12.3 & 53.93 & 22.4 & 65.89 & 11.6 & 34.11 \\
\hline Total & 26.9 & 41.66 & 37.7 & 58.34 & 64.1 & 25.13 & 190.9 & 74.87 \\
\hline
\end{tabular}

A corpus of 3,860 instances of adverbials and negative constituents occupying initial position was retrieved, of which 1,018 triggered inversion and 2,842 selected for SVO. In MEMT, nearly half the instances showed inversion (41.66\%). However, a different picture is witnessed between initial adverbials and negatives, as the former trigger inversion in $39.2 \%$ of the cases and the latter in $46.07 \%$. Therefore, these percentages lead us to conclude that initial negatives are slightly more prone to trigger inversion than initial adverbials, although in both cases the situation appears to be balanced.

A different tendency is observed in EMEMT, where $25.13 \%$ of the instances of fronted adverbials and negatives show inversion. In the light of these figures, fronted adverbials cause inversion at a rate of $18.8 \%$ and negatives do so in $67.11 \%$ of the instances. Thus, it can be safely said that in the EModE period SVO is preferred whenever an adverbial is fronted, and that inversion outnumbers SVO after an initial negative constituent. These results contrast with those obtained in Jacobsson's study on inversion after initial adverbials, as he found inversion after sentence-initial then, now, there, here, so, yet and therefore in almost half of the instances in 1370-1500 and even in the following century in one-third (Jacobsson 1951; see also Rissanen 1999: 264). Additionally, Bækken studied the phenomenon in an EModE corpus of half a dozen genres (religious prose, letters, documents, histories and geography), ${ }^{16}$ concluding that inversion after fronted adverbials fell from one out of five in 1500 to one out of ten in 1700 (1998: 60). In the data presented in Table 3, however, inversion after adverbials occurs at a rate of $39.2 \%$ in $M E M T$ and $18.2 \%$ in EMEMT, a fact leading us to conclude that inversion after fronted adverbials was more widespread in scientific writing than in other genres.

The normalized frequencies in Table 3 allow for the comparison of the two historical periods. Consequently, when it comes to inversion after fronted adverbials, it is nearly four times more frequent in EMEMT than in MEMT (41.6 over 16.3 instances, respectively). The case of initial negatives follows the same trend, 
in which the cases of inversion in EMEMT more than double those in $M E M T$ (22.4 over 10.5 instances). However, the different rates of SVO in each corpus do not allow us to see the wood for the trees inasmuch as, although the frequency of inversion is much higher in the EModE component, what becomes relevant here is the proportion of inversion and SVO in each corpus. Therefore, in the case of fronted adverbials, inversion decreases from $39.2 \%$ in $M E M T$ to $18.8 \%$ in EMEMT. Initial negatives, on the contrary, represent the other side of the coin, where inversion spreads from $46.07 \%$ in MEMT to $67.11 \%$ in EMEMT.

In addition, the EModE component has been subdivided into eight 25 -year subperiods in order to determine the historical moment in which fronted adverbials ceased to trigger inversion as frequently as they did in Middle English; and initial negatives started to cause it as they had previously done during the $\mathrm{OE}$ period. For the purpose, Figures 1 and 2 display the development of the phenomenon with fronted adverbials and fronted negatives, respectively. The figures have been normalized (per 100,000 words) so that the different subperiods can be compared to each other.

In Figure 1, inversion and SVO after fronted adverbials are offered, where the dotted lines indicate a decreasing tendency of the former which coincides with a moderate spread of the latter. In the case of adverbials not triggering inversion, the frequency rises from 103.3 to 229.4 instances after 1525 and then it remains relatively stable until the end of the period (164.2 instances in 1675-1700). As for the cases of inversion, even though they diffuse after 1525 from 28.5 to 92.8 , the frequency decreases progressively throughout the period, with 15.7 in 1675-1700. In addition, Kendall's Tau statistical analysis points to the fact that, after 1525, the decreasing tendency of inversion after fronted adverbials is significant at $p<0.05$ whereas the spread of SVO in these environments is not (Kendall 1970; see also Petré 2015: 44).

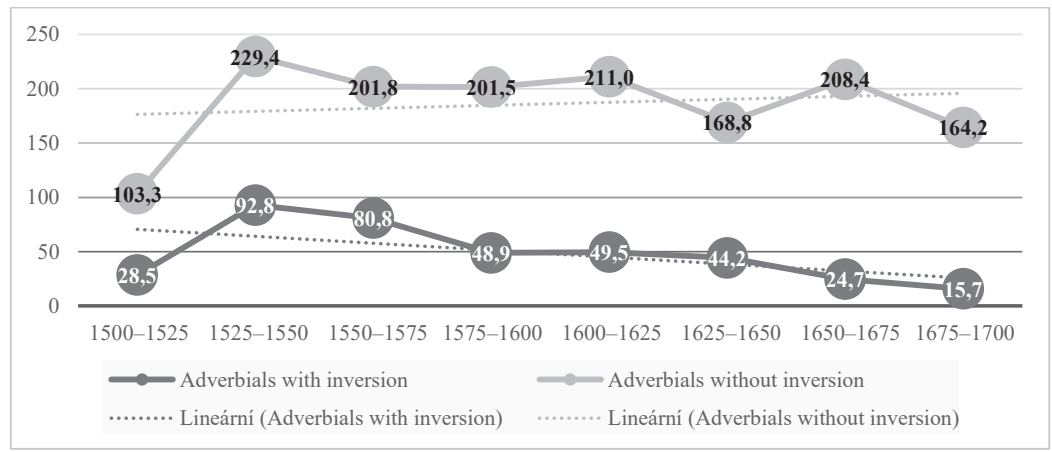

Figure 1. Inversion and SVO after fronted adverbials in EMEMT (n.f.)

Figure 2 displays the normalized frequencies for inversion after fronted negatives. In the case of fronted negatives with the order SVO, there is a gradual decrease from 33.9 to 8.8 in $1525-1550$ and $1675-1700$, respectively. Inversion 
after fronted negatives, in turn, diffuses widely throughout the period, spreading from 0 to 25.6 instances in 1500-1525 and 1675-1700, respectively. Furthermore, Kendall's Tau statistical analysis indicates that the increasing tendency of inversion after fronted negatives is significant at $p<0.05$ whereas the decrease of SVO in these contexts is not (Kendall 1970; see also Petré 2000: 44).

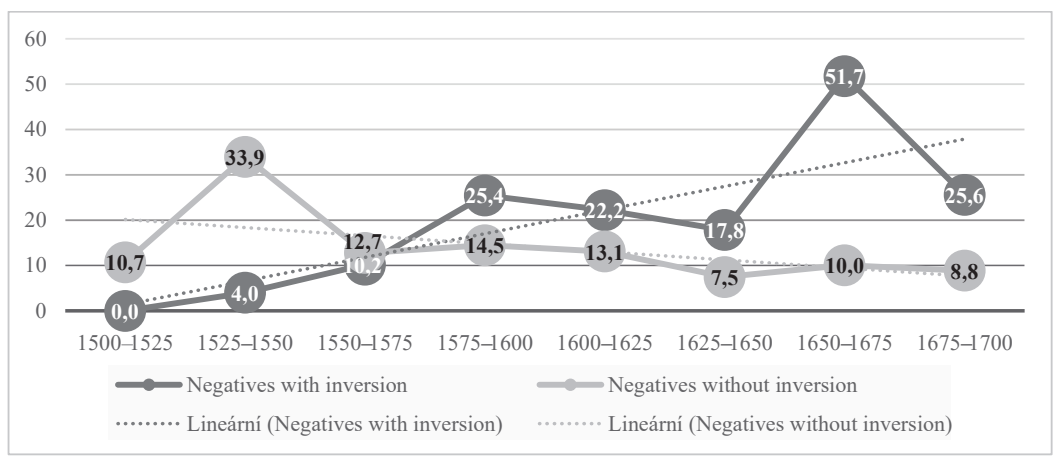

Figure 2. Inversion and SVO after fronted negatives in EMEMT (n.f.)

\subsection{Genre variation}

It has been elsewhere said that even though genres may not be responsible for particular linguistic changes, they certainly facilitate their spread, acting as catalysts insofar as they accelerate the diffusion of constructions that already exist in the language (Kohnen 2001: 115). The present section evaluates the phenomenon under study in the light of the different subgenres of the corpora. The corpora under study belong to the genre of scientific writing, which started to be produced in English during the 14th century. ${ }^{17}$ Thus, while in the initial phases of the process English would occur together with Latin and/or French in bi- or trilingual volumes, by the end of the fifteenth century "there was a full range of vernacular medical texts available in English-language manuscripts in which Latin played little or no role" (Pahta 2001: 209). ${ }^{18}$

Scientific writing in ME was, therefore, highly influenced by the scholastic Latin and/or French texts from which they were translated, which relied mainly on classical authors such as Galen or Hippocrates (Taavitsainen and Pahta 1998: 162). In EModE, in turn, new ways of constructing knowledge emerged, based on observation and cognition. This methodological change had its consequences on the language by which science was transmitted as, according to Taavitsainen (2011: 123-131), genres "constitute dynamic systems that undergo change and variation over the course of time as sociocultural needs change, and genres change accordingly: old genres are adapted to new functions, new genres are created, and genres that have lost their function cease to exist (Taavitsainen 2001: 141, 2009: 38). ${ }^{19}$

The number of instances showing inversion after fronted adverbials has been calculated across subgenres in Table 4, together with the normalized frequencies 
(per 100,000 words). It can be observed that both ME and EModE follow the same tendency, as SVO after a fronted adverbial is the commonest choice in all the subgenres. In terms of frequency, it could be said that EMEMT shows a higher number of instances of SVO than MEMT (18.54, 18.73 and 15.86 over 8.82, 1.37 and 0.72 instances in specialized texts, surgical texts and remedies, respectively). The instances of inversion, nevertheless, are more likely to be found in specialized texts in MEMT (4.86 over 4.22 instances per 100,000 words, respectively) and in surgical texts and remedies in EMEMT (2.91 and 5.13 over 1.23 and 0.59 instances per 100,000 words, respectively).

Table 4. Inversion after fronted adverbials across subgenres in MEMT and EMEMT

\begin{tabular}{|l|cc|cc|cc|cc|}
\cline { 2 - 9 } \multicolumn{1}{c|}{} & \multicolumn{4}{c|}{$M E M T$} & \multicolumn{4}{c|}{ EMEMT } \\
\cline { 2 - 9 } \multicolumn{1}{c|}{} & \multicolumn{2}{c|}{ Inversion } & \multicolumn{2}{c|}{ SVO } & \multicolumn{2}{c|}{ Inversion } & \multicolumn{2}{c|}{ SVO } \\
\cline { 2 - 9 } \multicolumn{1}{c|}{} & Raw & n.f. & Raw & n.f. & Raw & n.f. & Raw & n.f. \\
\hline Specialized treatises & 43 & 48.7 & 78 & 88.3 & 322 & 42.2 & 1414 & 185.4 \\
\hline Surgical treatises & 17 & 12.3 & 19 & 13.8 & 87 & 29.2 & 559 & 187.4 \\
\hline Remedies & 13 & 5.9 & 16 & 7.3 & 174 & 51.3 & 538 & 158.7 \\
\hline
\end{tabular}

When it comes to fronted negative constituents, ME and EModE follow divergent trends in such a way that the former is less likely to show inversion than the latter. Consequently, SVO is more frequent in surgical treatises and remedies (21.87 and 5.5 instances, respectively) and inversion is preferred in specialized treatises (15.8 instances). In EMEMT, in turn, there is an overwhelming preference for inversion in all subgenres (25.6, 21.1 and 16.8 over 12.1, 6.4 and 15.3 instances in specialized texts, surgical texts and remedies, respectively). These results show a development of word order after a fronted negative constituent, that is, from SVO in MEMT to inversion in EMEMT in specialized and surgical texts, remedies preferring inversion in both historical periods.

Table 5. Inversion after fronted negatives across subgenres in MEMT and EMEMT

\begin{tabular}{|l|cc|cc|cc|cc|}
\cline { 2 - 10 } \multicolumn{1}{c|}{} & \multicolumn{4}{c|}{ MEMT } & \multicolumn{4}{c|}{ EMEMT } \\
\cline { 2 - 10 } \multicolumn{1}{c|}{} & \multicolumn{2}{c|}{ Inversion } & \multicolumn{2}{c|}{ SVO } & \multicolumn{2}{c|}{ Inversion } & \multicolumn{2}{c|}{ SVO } \\
\cline { 2 - 9 } \multicolumn{1}{c|}{} & Raw & n.f. & Raw & n.f. & Raw & n.f. & Raw & n.f. \\
\hline Specialized treatises & 14 & 15.8 & 12 & 13.6 & 195 & 25.6 & 92 & 12.1 \\
\hline Surgical treatises & 23 & 16.7 & 30 & 21.8 & 63 & 21.1 & 19 & 6.4 \\
\hline Remedies & 10 & 4.6 & 12 & 5.5 & 57 & 16.8 & 52 & 15.3 \\
\hline
\end{tabular}

In addition to the analysis of inversion in the different subgenres as a whole, Figure 3 below provides the normalized frequencies (per 100,000 words) of inversion and SVO after fronted adverbials, according to the four 50 -year subperiods 
in EMEMT. As shown in all cases, the rate of SVO structures is much higher in all the subperiods, a fact coinciding with a progressive decrease of inversion. Therefore, it can be said that the obliteration of inversion was a general tendency that affected all EModE subgenres, where a progressive decrease of inversion is observed throughout the period.

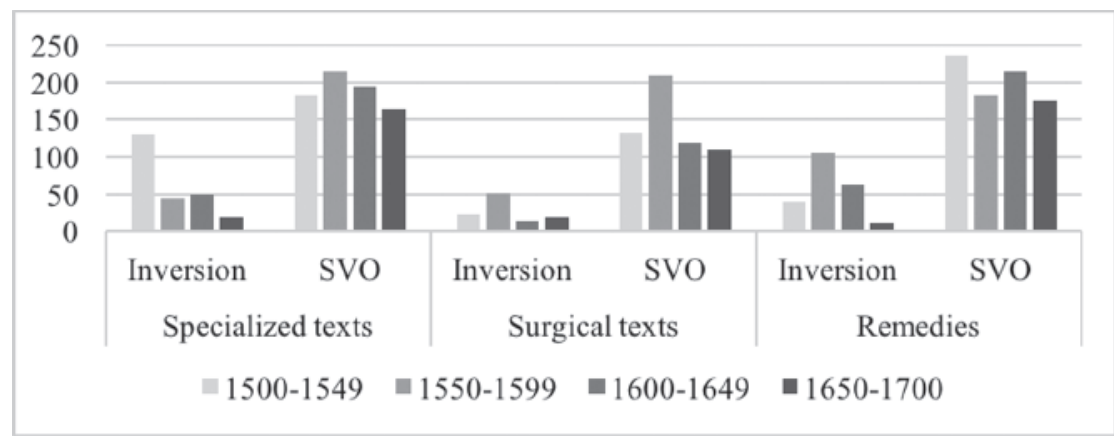

Figure 3. Development of inversion after fronted adverbials in EMEMT across subgenres (n.f.)

The use of inversion after fronted negative constituents is somewhat different. Thus, the spread of inversion, which coincides with the decline of the SVO pattern. Additionally, while inversion is more frequent at the end of EModE in surgical texts and remedies, SVO is still the dominant pattern in specialized texts.

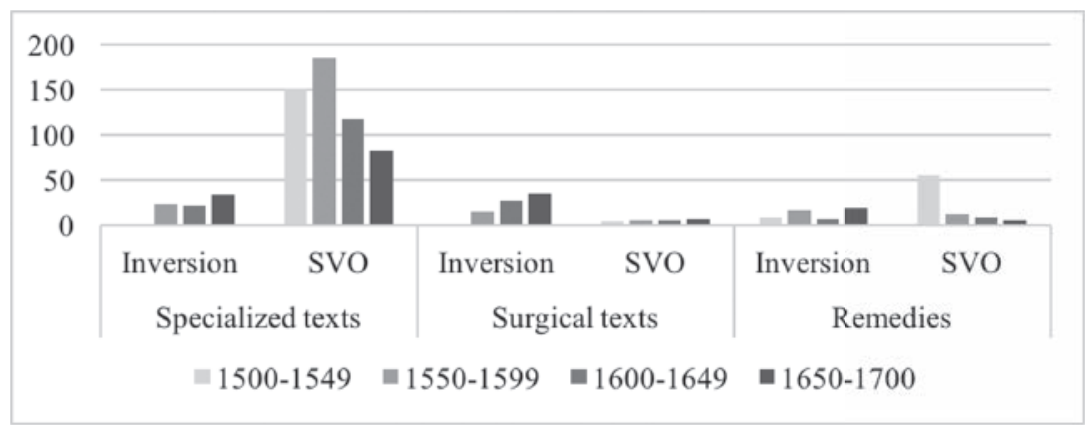

Figure 4. Development of inversion after fronted negatives in EMEMT across subgenres (n.f.)

\subsection{Conditioning factors}

This section assesses the contribution of the following factors in the choice of inversion or SVO after a fronted adverbial or negative constituent: 1) the typology of inversion; 2) the typology of the subject; and 3) the verbs subject to inversion in the corpora. 


\subsubsection{Full Inversion vs. Subject-Auxiliary Inversion}

The corpus of instances showing an inverted pattern has been classified in terms of the kind of inversion that they feature, whether full inversion (FI) or subjectauxiliary inversion (SAI), as in examples (16) and (17), respectively:

(16) Then will follow a conuulsion in that part. It is also as often caused by grosse humors. (EMEMT: 1632_Bruele_PraxisMedicinae).

(17) Then muste the mydwyfe tenderly take the chylde by the head. (EMEMT: 1540_Roesslin_ByrthOfMankynde)

Such a distinction is relevant in the present study insofar as "partially inverted structures are of considerable interest, as this order may be the result of two conflicting tendencies: the traditional verb-second and the innovative subject-verb (SV) order, the latter requiring an overt subject in front of the verb" (Baekken 2005: 413). For the purpose, Table 6 offers the raw frequencies, normalized figures (tokens per 100,000 words) and percentages of full inversion and subjectauxiliary inversion in $M E M T$ and EMEMT.

Table 6. Inversion types in MEMT and EMEMT ${ }^{20}$

\begin{tabular}{|c|ccc|ccc|ccc|ccc|}
\cline { 2 - 13 } \multicolumn{1}{c|}{} & \multicolumn{4}{c|}{ MEMT } & \multicolumn{5}{c|}{ EMEMT } \\
\cline { 2 - 13 } \multicolumn{1}{c|}{} & \multicolumn{3}{c|}{ FI } & \multicolumn{3}{c|}{ SAI } & \multicolumn{3}{c|}{ FI } & \multicolumn{3}{c|}{ SAI } \\
\cline { 2 - 13 } \multicolumn{1}{c|}{} & Raw & n.f. & $\%$ & Raw & n.f. & $\%$ & Raw & n.f. & $\%$ & Raw & n.f. & $\%$ \\
\hline Adv. & 3 & 0.7 & 7.3 & 38 & 8.5 & 92.7 & 22 & 1.6 & 6.3 & 330 & 23.6 & 93.8 \\
\hline Neg. & 3 & 0.7 & 21.4 & 11 & 2.5 & 78.6 & 10 & 0.7 & 4.8 & 199 & 14.2 & 95.2 \\
\hline
\end{tabular}

As can be observed, subject-auxiliary inversion is overwhelmingly preferred irrespective of the typology of the fronted element and the period. Additionally, the same tendency is witnessed in MEMT and EMEMT, as full inversion occurs as frequently with fronted adverbials as with fronted negative constituents and subject-auxiliary inversion occurs more widely with fronted adverbials. These data reveal that early English scientific writing is still in the transition from VS to SV in these environments, hence the higher occurrence of subject-auxiliary inversion (SAI).

\subsubsection{The typology of the subject}

When it comes to inversion in the history of English, the literature on the topic is somewhat limited inasmuch as many studies do not make a distinction between nominal and pronominal subjects, at least in quantitative terms (Fischer et al. 2004: 133). It has been elsewhere noted that the 'weight' of the finite verb and the subject may influence their mutual order, that is, "there is a strong tendency 
for pronominal subjects to occur in second position following an initial element, i.e. non-inversion is the normal pattern, while the inverted order most typically features full noun-phrase subjects" (Nevalainen 1997: 211; see also Fischer 1992: 375; Risanen 1999: 264; Bækken 2000: 409). ${ }^{21}$

In the light of this, Table 7 shows the instances of inversion and SVO with both nominal and pronominal subjects in MEMT. According to Fischer et al. (2004: 106), in ME, subject-verb inversion is compulsory when the first constituent is a question element of the negative adverbial $n e$, both with nominal and pronominal subjects. In our data, the nature of the subject is important in the choice of the word-order pattern in ME medical writing, as pronominal subjects are more widely attested with SVO and nominal subjects are more bound to occur with inversion. Thus, in those clauses with inversion, approximately $60 \%$ of the instances feature a pronominal subject and $40 \%$ a nominal subject, both after fronted adverbials and fronted negative constituents. With SVO, the number of nominal subjects decreases slightly while the number of pronominals is higher $(34.5 \%$ for nominals and $65.5 \%$ for pronominals, both after fronted adverbials and fronted negative constituents).

Table 7. Typology of the subject in MEMT

\begin{tabular}{|c|c|c|c|c|c|c|c|c|}
\hline & \multicolumn{8}{|c|}{ MEMT } \\
\hline & \multicolumn{4}{|c|}{ Inversion } & \multicolumn{4}{|c|}{$S V O$} \\
\hline & \multicolumn{2}{|c|}{ Nominal } & \multicolumn{2}{|c|}{ Pronominal } & \multicolumn{2}{|c|}{ Nominal } & \multicolumn{2}{|c|}{ Pronominal } \\
\hline & Raw & $\%$ & Raw & $\%$ & Raw & $\%$ & Raw & $\%$ \\
\hline Adverbials & 31 & 42.4 & 42 & 57.6 & 39 & 34.5 & 74 & 65.5 \\
\hline Negatives & 19 & 40.4 & 28 & 59.6 & 19 & 34.5 & 36 & 65.5 \\
\hline Total & 50 & 41.6 & 70 & 58.4 & 58 & 34.5 & 110 & 65.5 \\
\hline
\end{tabular}

The same classification has been made for EMEMT in Table 8. As shown, the situation in EMEMT contrasts with that of MEMT. Consequently, after fronted adverbials, pronominal subjects are more widely witnessed both with inversion and SVO (53.1\% and 59.9,\% respectively). After fronted negatives, in turn, pronominal subjects are preferred with inversion (58.4\%) and nominal subjects are more frequently attested with SVO (72.4\%).

Table 8. Typology of the subject in EMEMT

\begin{tabular}{|c|c|c|c|c|c|c|c|c|}
\hline & \multicolumn{8}{|c|}{ EMEMT } \\
\hline & \multicolumn{4}{|c|}{ Inversion } & \multicolumn{4}{|c|}{ SVO } \\
\hline & \multicolumn{2}{|c|}{ Nominal } & \multicolumn{2}{|c|}{ Pronominal } & \multicolumn{2}{|c|}{ Nominal } & \multicolumn{2}{|c|}{ Pronominal } \\
\hline & Raw & $\%$ & Raw & $\%$ & Raw & $\%$ & Raw & $\%$ \\
\hline Adverbials & 274 & 46.9 & 309 & 53.1 & 1,007 & 40.1 & 1,504 & 59.9 \\
\hline Negatives & 128 & 41.6 & 187 & 58.4 & 118 & 72.4 & 45 & 27.6 \\
\hline Total & 402 & 44.8 & 496 & 55.2 & 1,125 & 42.1 & 1,549 & 57.9 \\
\hline
\end{tabular}


The results above contrast with those obtained by Bækken (2000: 409), where he found $72.4 \%$ and $52.8 \%$ of pronominal subjects and nominal subjects with SVO and inversion, respectively. The data obtained in the present study, however, reveals that the situation is somewhat more balanced, pronominal subjects outstandingly diffusing with inversion and SVO, both after fronted adverbials and negative constituents in MEMT. In EMEMT, pronominals are preferred in inverted and non-inverted structures after fronted adverbials. After fronted negatives, in turn, pronominals are preferred with inversion while nominal subjects are usually the choice with SVO.

In addition, nominal subjects have been further subdivided according to their length, that is, whether they are light noun phrases (those with a single noun or adjective + noun) or heavy noun phrases (coordinated phrases, relative clauses and noun phrases containing prepositional phrases in a series) to determine whether these features have an influence on the phenomenon (see Calle-Martín and Romero-Barranco 2017). For the purpose, Table 9 and 10 present the data in $M E M T$ and EMEMT, respectively, according to the nature of the NP subjects, either light or heavy. In MEMT, on the one hand, light subjects are more prone to occur with fronted adverbials and negative constituents, their rates being always above $78 \%$, both in inverted and non-inverted structures. In EMEMT, on the other, the same picture is observed, where light subjects are more frequently witnessed, even though heavy subjects show a higher percentage if compared to the data found in MEMT.

Table 9. The length of nominal subjects in MEMT

\begin{tabular}{|c|c|c|c|c|c|c|c|c|}
\hline & \multicolumn{8}{|c|}{ Nominal Subjects } \\
\hline & \multicolumn{4}{|c|}{ Inversion } & \multicolumn{4}{|c|}{ SVO } \\
\hline & \multicolumn{2}{|c|}{ Light } & \multicolumn{2}{|c|}{ Heavy } & \multicolumn{2}{|c|}{ Light } & \multicolumn{2}{|c|}{ Heavy } \\
\hline & Raw & $\%$ & Raw & $\%$ & Raw & $\%$ & Raw & $\%$ \\
\hline Adverbials & 29 & 93.5 & 2 & 6.5 & 33 & 84.6 & 6 & 15.4 \\
\hline Negatives & 17 & 89.5 & 2 & 10.5 & 15 & 78.9 & 4 & 21.1 \\
\hline Total & 46 & 92 & 4 & 8 & 48 & 82.8 & 10 & 17.2 \\
\hline
\end{tabular}

Table 10. The length of nominal subjects in EMEMT

\begin{tabular}{|c|c|c|c|c|c|c|c|c|}
\hline & \multicolumn{8}{|c|}{ Nominal Subjects } \\
\hline & \multicolumn{4}{|c|}{ Inversion } & \multicolumn{4}{|c|}{ SVO } \\
\hline & \multicolumn{2}{|c|}{ Light } & \multicolumn{2}{|c|}{ Heavy } & \multicolumn{2}{|c|}{ Light } & \multicolumn{2}{|c|}{ Heavy } \\
\hline & Raw & $\%$ & Raw & $\%$ & Raw & $\%$ & Raw & $\%$ \\
\hline Adverbials & 219 & 79.9 & 55 & 20.1 & 800 & 79.4 & 207 & 20.6 \\
\hline Negatives & 82 & 64.1 & 46 & 35.9 & 83 & 70.3 & 35 & 29.7 \\
\hline Total & 301 & 74.9 & 101 & 25.1 & 883 & 78.5 & 242 & 21.5 \\
\hline
\end{tabular}




\subsubsection{Inverted verbs}

The present section classifies the different verbs with which inversion and SVO take place in order to ascertain whether this factor contributes to the choice of a particular word-order pattern. According to Rissanen, verbs such as have, say, come and stand favour inversion in seventeenth-century texts (1999: 264). Following this thread, Fischer et al. warn about the need of quantitative analyses "with special attention to a distinction between lexical finite verbs and modals and other auxiliaries in the making in the fifteenth century and perhaps to possible differences between texts that reflect colloquial speech more closely" (2004: 134).

Accordingly, Tables 11 and 12 provide the proportion of simple verb forms (i.e. lexical verbs) as opposed to Aux + Verb (auxiliaries, modals and the copula) after fronted adverbials and negative constituents, respectively. As can be observed, after fronted adverbials, MEMT and EMEMT present the same situation, in which the rates of Aux $+\mathrm{V}$ outnumber the rates of simple verbs, both in inverted and non-inverted constructions (Table 11). After fronted negative constituents (Table 12), however, the situation is somewhat different. In MEMT, simple verbs are more frequent $(70.2 \%)$ in inverted constructions whereas Aux $+\mathrm{V}$ is more widely witnessed $(65.5 \%)$ in SVO structures. EMEMT, in turn, contrasts with MEMT, as Aux $+\mathrm{V}$ is preferred in inverted structures $(89.2 \%)$ and simple verbs in SVO structures $(54.9 \%)$.

Table 11. Simple verb vs. Aux $+V$ after fronted adverbials in MEMT and EMEMT

\begin{tabular}{|c|c|c|c|c|c|c|c|c|}
\cline { 2 - 9 } \multicolumn{1}{c|}{} & \multicolumn{4}{c|}{ MEMT } & \multicolumn{4}{c|}{ EMEMT } \\
\cline { 2 - 9 } \multicolumn{1}{c|}{ Inversion } & \multicolumn{2}{c|}{ SVO } & \multicolumn{2}{c|}{ Inversion } & \multicolumn{2}{c|}{ SVO } \\
\cline { 2 - 9 } \multicolumn{1}{c|}{} & Raw & $\%$ & Raw & $\%$ & Raw & $\%$ & Raw & $\%$ \\
\hline Simple V & 26 & 35.6 & 46 & 40.7 & 116 & 19.9 & 960 & 38.2 \\
\hline Aux $+\mathrm{V}$ & 47 & 64.4 & 67 & 59.3 & 467 & 80.1 & 1,551 & 61.8 \\
\hline
\end{tabular}

Table 12. Simple verb vs. Aux $+V$ after fronted negatives in MEMT and EMEMT

\begin{tabular}{|c|c|c|c|c|c|c|c|c|}
\cline { 2 - 9 } \multicolumn{1}{c|}{} & \multicolumn{4}{c|}{ MEMT } & \multicolumn{4}{c|}{ EMEMT } \\
\cline { 2 - 9 } \multicolumn{1}{c|}{ Inversion } & \multicolumn{2}{c|}{ SVO } & \multicolumn{2}{c|}{ Inversion } & \multicolumn{2}{c|}{ SVO } \\
\cline { 2 - 9 } & Raw & $\%$ & Raw & $\%$ & Raw & $\%$ & Raw & $\%$ \\
\hline Simple V & 33 & 70.2 & 19 & 34.5 & 38 & 10.8 & 96 & 54.9 \\
\hline Aux + V & 14 & 29.8 & 36 & 65.5 & 315 & 89.2 & 79 & 45.1 \\
\hline
\end{tabular}

Table 13 shows the normalized frequencies and the percentage of instances with fronted adverbials according to the kind of verb with which they occur, both inverted and non-inverted. As shown, particular tendencies are observed when it comes to the typology of verbs. In MEMT, on the one hand, SVO structures are more frequently attested with lexical verbs (10.3 instances), followed by the 
copula (8.1 instances) and modals (6.7 instances), while inverted structures occur more widely after auxiliaries (0.9 instances). In EMEMT, on the other, all verb types show SVO more frequently, this pattern occurring at a rate of more than $65 \%$ in all the cases.

Table 13. Verbs after fronted adverbials

\begin{tabular}{|c|c|c|c|c|c|c|c|c|}
\cline { 2 - 9 } \multicolumn{1}{c|}{} & \multicolumn{4}{c|}{ MEMT } & \multicolumn{4}{c|}{ EMEMT } \\
\cline { 2 - 9 } \multicolumn{1}{c|}{ Inversion } & \multicolumn{2}{c|}{ SVO } & \multicolumn{2}{c|}{ Inversion } & \multicolumn{2}{c|}{ SVO } \\
\cline { 2 - 9 } \multicolumn{1}{c|}{} & $n . f$ & $\%$ & $n . f$ & $\%$ & $n . f$ & $\%$ & $n . f$ & $\%$ \\
\hline Lexical & 5.8 & 36.1 & 10.3 & 63.9 & 8.3 & 10.8 & 68.6 & 89.2 \\
\hline Auxiliary & 0.9 & 80 & 0.2 & 20 & 5.4 & 31.8 & 11.5 & 68.2 \\
\hline Modal & 6.1 & 47.4 & 6.7 & 52.6 & 15.9 & 24.4 & 49.2 & 75.6 \\
\hline Copula & 3.6 & 30.8 & 8.1 & 69.2 & 12.1 & 19.5 & 50.1 & 80.5 \\
\hline
\end{tabular}

Furthermore, Table 14 shows the instances with fronted negative constituents classified according to the type of verb. As shown, there is a clear preference in $M E M T$ for SVO structures, the only exception being the instances with lexical verbs (inversion in $63.5 \%$ of the instances). In EMEMT, in turn, the figures indicate the opposite picture, where inversion is the choice with all verbs except for lexical verbs.

Table 14. Verbs after fronted negative constituents

\begin{tabular}{|c|c|c|c|c|c|c|c|c|}
\cline { 2 - 9 } \multicolumn{1}{c|}{} & \multicolumn{4}{c|}{ MEMT } & \multicolumn{4}{c|}{ EMEMT } \\
\cline { 2 - 9 } \multicolumn{1}{c|}{ Inversion } & \multicolumn{2}{c|}{ SVO } & \multicolumn{2}{c|}{ Inversion } & \multicolumn{2}{c|}{ SVO } \\
\cline { 2 - 9 } & $n . f$ & $\%$ & $n . f$ & $\%$ & $n . f$ & $\%$ & $n . f$ & $\%$ \\
\hline Lexical & 7.4 & 63.5 & 4.3 & 36.5 & 2.7 & 28.4 & 6.9 & 71.6 \\
\hline Auxiliary & 0.0 & 0.0 & 1.3 & 100.0 & 5.1 & 92.3 & 0.4 & 7.7 \\
\hline Modal & 2.0 & 34.6 & 3.8 & 65.4 & 7.9 & 68.8 & 3.6 & 31.3 \\
\hline Copula & 1.1 & 27.8 & 2.9 & 72.2 & 9.5 & 85.3 & 1.6 & 14.7 \\
\hline
\end{tabular}

These results show that there were differences between $M E M T$ and $E M E M T$ when it comes to the typology of verbs. Thus, while in MEMT both inverted and noninverted structures occur more frequently with lexical verbs when an adverbial or a negative constituent is fronted, there is not such a distribution in EMEMT, inversion occurring more frequently with modals and the copula and SVO with lexical verbs. This being so, it could be stated that lexical verbs were rarely inverted in the EModE period, when the frequency of modals and the copula spread in these contexts. In addition, the results obtained with regard to auxiliaries must be noted. According to Fischer et al. (2004: 105), in ME, inversion in negativeinitial clauses is restricted to auxiliaries, however, our data show a different pic- 
ture, auxiliaries being not found within the typology of verbs with inversion after negative constituents.

Finally, one more perspective is needed when it comes to the typology of verbs and the typology of the subject in the previous section. For the purpose, Table 15 offers the the distribution of the phenomenon according to the typology of the subject and verb, in order to ascertain if there is a pattern between these two variables. As observed, when an adverbial is fronted, pronominal subjects occur more frequently with modals in $M E M T$ and $E M E M T$, while nominal subjects do so with lexical verbs in $M E M T$ and the copula in EMEMT. Additionally, when the fronted element is a negative constituent, pronominal subjects tend to be inverted more widely with lexical verbs in $M E M T$ and nominal subjects do so with the copula, while in EMEMT both pronominal and nominal subjects are more widely attested with the copula.

Table 15. The nature of the subject and inverted verbs (n.f.)

\begin{tabular}{|l|cccc|cccc|}
\cline { 2 - 9 } \multicolumn{1}{c|}{} & \multicolumn{4}{c|}{ MEMT } & \multicolumn{4}{c|}{ EMEMT } \\
\cline { 2 - 9 } \multicolumn{1}{c|}{} & Lexical & Aux. & Modal & Copula & Lexical & Aux. & Modal & Copula \\
\hline Adv. + Pron. Subj. & 26.9 & 0.9 & 4.9 & 0.9 & 3.4 & 3.6 & 9.7 & 5.3 \\
\hline Adv. + Nom. Subj. & 31.4 & 0.0 & 1.6 & 2.2 & 4.9 & 1.7 & 6.0 & 7.1 \\
\hline Neg. + Pron. Subj. & 44.9 & 0.0 & 1.8 & 0.0 & 0.7 & 2.9 & 4.7 & 4.9 \\
\hline Neg. + Nom. Subj. & 29.2 & 0.0 & 0.2 & 1.1 & 2.5 & 0.4 & 2.4 & 4.1 \\
\hline
\end{tabular}

\section{Concluding remarks}

The present paper has studied the phenomenon of inversion after fronted adverbials and negative constituents in a corpus of Middle English and early Modern English scientific prose. In addition to the use and distribution of the phenomenon in these periods and across genres, the study has assessed the contribution of aspects such as the kind of inversion, the typology of the subject and the taxonomy of inverted verbs. The following conclusions have been obtained.

First, the data reveal that inversion after fronted adverbials decreased during the EModE period, a fact which coincides with the diffusion of inversion after fronted negative constituents. More importantly, inversion after fronted adverbials suffers the most drastic drop after 1550. Inversion after fronted negative constituents, in turn, spreads progressively throughout the period, especially after 1550 and again after 1650. By the end of the EModE period, the construction occurs twice as many times as inversion after fronted adverbials in scientific writing.

Second, the analysis in terms of genre has revealed that MEMT and EMEMT show similarities and divergences towards inversion and SVO after fronted adverbials and negative constituents. On the one hand, after a fronted adverbial, 
SVO is the preferred word-order pattern in all subgenres in both historical periods. On the other, after fronted negative constituents, MEMT features SVO more frequently in surgical texts and remedies and inversion in specialized texts, whereas EMEMT opts for inversion in all subgenres.

Third, the analysis of the construction has demonstrated that full inversion is scarce in the corpora under study, while subject-auxiliary inversion is more widely witnessed with fronted adverbials than with fronted negative constituents.

Fourth, the assessment of the typology of the subject shows that pronominal subjects are more widely attested after fronted adverbials or negative constituents in $M E M T$. In EMEMT, in turn, pronominal subjects are preferred with inversion while nominal subjects are more frequent with SVO. Besides, nominal subjects were classified according to their nature (i.e. light or heavy) and the data reveals that light nominal subjects are more prone to occur after fronted adverbials and negative constituents in both $M E M T$ and EMEMT.

Finally, the taxonomy of inverted verbs shows that there are particular preferences towards the choice of SVO or inversion in MEMT and EMEMT. On the one hand, in $M E M T$, inversion occurs more frequently with modals after fronted adverbials and with lexical verbs after negative constituents. In addition, SVO occurs more widely with lexical verbs after fronted adverbials and negative constituents. On the other, in EMEMT, inversion is more widely attested with modals after fronted adverbials and with the copula after fronted negatives, while SVO is more frequently witnessed with lexical verbs. In addition, if this classification is combined with the typology of the subject, we find that, with a fronted adverbial, pronominal and nominal subjects occur more frequently with lexical verbs in $M E M T$ and with modals in EMEMT. After a fronted negative constituent, in turn, pronominal and nominal subjects tend to be inverted more widely with lexical verbs in MEMT and with the copula in EMEMT.

To sum up, the results obtained in the present paper have demonstrated that inverted structures after fronted adverbials became uncommon in scientific English later than in other genres (religious prose, letters, etc.), while inversion after fronted negatives spread considerably in the early Modern English period. Corpus-based studies on scientific writing are particularly relevant when it comes to the study of the History of English as 1) English scientific prose led the process by which the English language was re-adopted as the language in England (see Taavitsainen and Pahta 2004); and 2) English scientific writing is representative of all the English-speaking community, where theoretical treatises stand for the most learned circles and remedies do so for the language used by lay people, surgical treatises falling in-between these two. Consequently, the peculiarities of English scientific writing with regard to inverted structures may be conceived as stylistic rather than grammatical (Fischer et al. 2004: 133), as they could be certainly attached to the features of scientific writing as a genre, hence the need of similar approaches in other genres and registers that may shed new light on the phenomenon. 


\section{Notes}

1 The present research has been funded by the Spanish Ministry of Science and Innovation (grant number FFI2014-57963-P) and by the Autonomous Government of Andalusia (grant number P11-HUM7597). These grants are hereby gratefully acknowledged. Dr Javier CalleMartín and Soluna Salles-Bernal (University of Málaga) deserve sincerest gratitude for their valuable help in the quantitative analysis. I am also grateful to the two anonymous referees of Brno Studies in English, whose thoughtful comments have substantially improved the final version of this article. According to Greenberg (1966: 76), the vast majority of languages have several variant orders but a single dominant one, the most common being VOS, OSV, and OVS.

Biber et al. also identify special cases of inversion which are mainly archaic expressions with literary overtones, such as May God forgive you your blasphemy (2002: 409). These elements would normally occupy another position within the clause and hence they trigger (obligatorily or optionally) inversion. In addition, Dorgeloh argues that "the sentenceinitial position potentially has wider discourse relevance and is thus a particularly promising candidate for the function of a positional choice in discourse" (1997: 21).

Traugott argues that PDE still retains some verb-final characteristics such as instances in which the adjective follows the noun (the only rivers navigable are) or the famous Saxon genitive, among others. In this vein, Traugott states that these verb-final remnants are due to the fact that the transition from verb-final to verb non-final has not been completed in all parts of grammar, "and so it is far from certain that PDE will ever become rigidly VO" (Traugott 1992: 274).

$6 \quad$ Fischer and van der Wurff point out that in OE main declarative sentences verb-second is frequent (except in cases when the initial element is a disjunct, sentence adverbial or a clause constituent; and when the subject of the sentence is pronominal). Furthermore, when $p a$ is in initial position, verb-second is triggered even with a pronominal subject (2006: 184).

$7 \quad$ Stockwell (1984: 581-582) lists the different classes of frontable constituents that trigger V2 optionally: 1) directional adverbs (i.e. through the half open windows drifted the mingled smell of wood smoke and freshmen); 2) locative adverbs (i.e. outside stood a little angel); 3) point time adverbs (i.e. soon after began the busy and important part of Swift's life); 4) manner adverbs (i.e. most humbly do I take my leave); 5) sequential adverbs (i.e. next came the middlesized Billy Goat Gruff); 6) quotations (i.e. 'we could have another fair', suggested Arthur). In relation to this, Haeberli (2007: 16) argues that "the only exception to this observation can be found in some specific contexts [...] such as questions, negative clauses and clauses introduced by some short adverbs [...] where subject-verb inversion also occurs with pronominal subjects.

Van Kemenade argues that "the change from OV to VO is well-documented and must be assumed to have been completed by 1200 , [while] the loss of V2 must be dated rather later, around 1400" (1987: 175).

In Jacobsson's approach to inversion after adverbials in EModE (1951), the sharpest drop takes place around 1600 .

According to Nevalainen (2006: 114), the lifting of the verb-second rule also licensed the inversion after clause-initial negative elements, which "gained ground rapidly and became fully established in the seventeenth century". In this vein, Wallage (2012: 9) argues that inversion following negative arguments and negative adverbials is witnessed before the seventeenth century, being established during the twelfth and thirteenth centuries.

Rissanen argues that "with negative particles and adverbs, such as never, neither, nor, the inverted order seems to become a rule in the seventeenth century; with other adverbials with a negative force, such as seldom, hardly, somewhat later" (Rissanen 1999: 265).

In the sections that follow, the term 'adverbial' will be used to label the group then, therefore, yet and thus; while the term 'negative' will be employed to refer to the group ne, neither, never and nor. 


\section{Sources}

EMEMT = Early Modern English Medical Texts. 2010. Compiled by Irma Taavitsainen, Päivi Pahta, Turo Hiltunen, Martti Mäkinen, Ville Marttila, Maura Ratia, Carla Suhr \& Jukka Tyrkkö. CD-ROM with EMEMT Presenter software by Raymond Hickey. Amsterdam/Philadelphia: John Benjamins.

MEMT = Middle English Medical Texts. 2005. Compiled by Irma Taavitsainen, Päivi Pahta \& Martti Mäkinen. CD-ROM with MEMT Presenter software by Raymond Hickey. Amsterdam/ Philadelphia: John Benjamins.

\section{References}

Bækken, Bjørg (1998) Word Order Patterns in Early Modern English. Oslo: Novus Press. Bækken, Bjørg (2000) 'Inversion in Early Modern English'. English Studies 81(5), 393-421.

Bækken, Bjørg (2005) 'Some Aspects of Word Order in Seventeenth-century English'. English Studies 86(6), 511-535.

Biber, Douglas, Stig Johansson, Geoffrey Leech, Susan Conrad and Edward Finegan (1999) Longman Grammar of Spoken and Written English. London: Longman.

Breivik, Leiv Egil and Toril Swan (1994) 'Initial Adverbials and Word Order in English with Spetial Reference to the Early Modern English Period'. In: Dieter Kastovsky (ed.) Studies in Early Modern English. Berlin and New York: Mouton de Gruyter, 11-44. 
Calle-Martín, Javier and Antonio Miranda-García (2010) 'Gehyrdon ge peet gecweden woes A Corpus-based Approach to Verb-initial Constructions in Old English'. Studia Neophilologica 82(1), 49-57.

Calle-Martín, Javier and Jesús Romero-Barranco (2014) 'On the Use of that/zero as Object Clause Links in Early English Medical Writing'. Studia Neophilologica 86(1), 1-16.

Calle-Martín, Javier and Jesús Romero-Barranco (2015) 'On the Use of make to vs. make ø in early English Medical Writing'. Atlantis: Journal of the Spanish Association of Anglo-American Studies 37(1), 157-177.

Calle-Martín, Javier and Jesús Romero-Barranco (2017) 'Third Person Present Tense Markers in some Varieties of English'. English World-Wide 37(2), forthcoming.

Carter, Ronald and Michael McCarthy (2006) Cambridge Grammar of English. Cambridge: Cambridge University Press.

Fischer, Olga (1992) 'Syntax'. In: Norman Blake (ed.) The Cambridge History of the English Language. Volume II. 1066-1476, 207-408. Cambridge: Cambridge University Press, 207-408.

Fischer, Olga, Ans van Kemenade, Willem Koopman and Wim van der Wurff (2004) The Syntax of Early English. Cambridge: Cambridge University Press.

Fischer, Olga and William van der Wurff (2006) 'Syntax'. In: Richard Hogg and David Denison (eds.) A History of the English Language. Cambridge: Cambridge University Press, 109-198.

Green, Georgia M. (1980) 'Some Wherefores of English Inversions'. Language 56(3), 582-601.

Greenberg, Joseph H. (1966) 'Some Universals of Grammar with Particular Reference to the Order of Meaningful Elements'. In: Joseph H. Greenberg (ed.) Universals of Language. Massachusetts: The Massachusetts Institute of Technology, 73-113.

Haeberli, Eric (2007) 'The Development of Subject-verb Inversion in Middle English and the Role of Language Contact'. Generative Grammar in Geneva 5, 15-33.

Haeberli, Eric and Richard Ingham (2007) 'The Position of Negation and Adverbs in Early Middle English'. Lingua 117, 1-25.

Hogg, Richard (2002) An Introduction to Old English. Edinburgh: Edinburgh University Press.

Ingham, Richard (2007) 'NegP and Negated Constituent Movement in the History of English'. Transactions of the Philological Society 105(3), 365-397.

Jacobsson, Bengt (1951) Inversion in English with Special Reference to the Early Modern English Period. Uppsala: Almqvist \& Wiksells Boktryckeri Ab.

van Kemenade, Ans (1987) Syntactic Case and Morphological Case in the History of English. Dordrecht: Foris.

Kendall, Maurice George (1970) Rank Correlation Methods. London: Griffin.

Kohnen, Thomas (2001) 'Text Types as Catalysts for Language Change'. In: Hans-Jürgen Diller and Manfred Görlach (eds.) Towards a History of English as a History of Genres. Heidelverg: Winter, 111-126.

Nevalainen, Terttu (1997) 'Recycling inversion: The case of initial adverbs and negators in Early Modern English'. Studia Anglica Posnaniensia 31, 203-214.

Nevalainen, Terttu (2006) An Introduction to Early Modern English. Edinburgh: Edinburgh University Press.

Pahta, Päivi (2001) 'Creating a New Genre: Contextual Dimensions in the Production and Transmission of Early Scientific Writing'. European Journal of English Studies 5(2), 205-220.

Petré, Peter (2015) 'Grammaticalization by Changing Co-text Frequencies, or Why [BE Ving ] Became the 'Progressive". English Language and Linguistics 20(1), 31-54.

Rissanen, Matti (1999) 'Syntax'. In: Roger Lass (ed.) A History of the English Language. Cambridge: Cambridge University Press, 187-326.

Robbins, Rossel Hope (1970) 'Medical Manuscripts in Middle English'. Speculum 45, 393-415.

Stockwell, Robert P. (1984) 'On the History of the Verb-Second Rule in English'. In: Jacek Fisiak (ed.) Historical Syntax. Berlin, New York and Amsterdam: Mouton Publishers, 575-592.

Taavitsainen, Irma (1994) 'On the Evolution of Scientific Writings from 1375 to 1675: Repertoire of Emotive Features'. In: Francisco Moreno-Fernández, Miguel Fuster and Juan José Calvo 
(eds.) English Historical Linguistics 1992. Amsterdam and Philadelphia: John Benjamins Publishing Company, 329-342.

Taavitsainen, Irma (2001) 'Changing Conventions of Writing: the Dynamics of Genres, Text Types, and Text Traditions'. European Journal of English Studies 5(2) 139-150.

Taavitsainen, Irma (2002) 'Historical Discourse Analysis: Scientific Language and Changing Thought-styles'. In: Teresa Fanego, Belén Méndez-Naya and Elena Seoane (eds.) Sounds, Words, Texts and Change. Selected Papers from 11 ICEHL, Santiago de Compostela, 7-11 September 2000. Amsterdam \& Philadelphia: John Benjamins Publishing Company, 201-226.

Taavitsainen, Irma (2009) 'The Pragmatics of Knowledge and Meaning: Corpus Linguistic Approaches to Changing Thought-styles in Early Modern Medical Discourse'. In: Andreas H. Jukker, Daniel Schreier and Marianne Hundt (eds.) Corpora: Pragmatics and Discourse. Amsterdam and New York: Rodopi, 37-62.

Taavitsainen, Irma and Päivi Pahta (1998) 'Vernacularisation of Medical Writing in English: A Corpus-Based Study of Scholasticism'. Early Science and Medicine 3(2), 157-185.

Taavitsainen, Irma and Päivi Pahta (2004) Medical and Scientific Writing in Late Medieval English. Cambridge: Cambridge University Press.

Taavitsainen, Irma and Päivi Pahta (2011) Medical Writing in Early Modern English. Cambridge: Cambridge University Press.

Traugott, Elizabeth Closs (1992) 'Syntax'. In: Richard M. Hogg (ed.) The Cambridge History of the English Language. Volume I: The beginnings to 1066. Cambridge: Cambridge University Press, 168-289.

Wallage, Phillip (2012) 'Negative Inversion, Negative Concord and Sentential Negation in the History of English'. English Language and Linguistics 16(1), 3-33.

Jesús Romero-BARRANCo is a member of the Department of English at the University of Malaga (Spain), where he is also a researcher in a project pursuing the electronic edition of unedited Early Modern English Fachliteratur. His research interests lie within the fields of palaeography, codicology, ecdotics and historical linguistics, in addition to corpus linguistics. He has published in a number of important international journals, such as Atlantis (Journal of the Spanish Association for Anglo-American Studies), Studia Neophilologica, Nordic Journal of English Studies and English World-Wide.

Address: Jesús Romero Barranco, Universidad de Málaga, Departamento de Filología Inglesa, Francesa y Alemana, Campus de Teatinos s/n, Málaga 29071, Spain. [email: jromer@uma.es] 
